\title{
A JOINT EDUCATION PROGRAM IN ONLINE DISTANCE LEARNING MODE FOR NORTH EASTERN REGION OF INDIA
}

\author{
Anjan Debnath ${ }^{1}$, P. L. N. Raju ${ }^{1}$, Victor Saikhom ${ }^{1}$, Harish C. Karnatak ${ }^{2}$ \\ ${ }^{1}$ North Eastern Space Applications Centre, Department of Space, Government of India, Umiam, Meghalaya, India - \\ anjan.debnath@nesac.gov.in,plnraju@gmail.com,victor.saikhom@gmail.com \\ ${ }^{2}$ Indian Institute of Remote Sensing, Indian Space Research Organization, Government of India, Dehradun, India - \\ harish@iirs.gov.in
}

Commission V, WG V/6

KEY WORDS: Online training, Distance Learning, NESAC Outreach, Capacity Building, IIRS Elearning.

\begin{abstract}
:
North Eastern Region of India is a picturesque land of seven sister states of Assam, Arunachal Pradesh, Meghalaya, Mizoram, Manipur, Nagaland, Tripura \& the state of Sikkim. The geography of the region is dominated by undulating hilly terrain comprising of Khasi \& Garo Hills in Meghalaya, Mizo \& Lusai Hills in Mizoram, Patkai Hills in Nagaland and Arunachal Himalayas in Arunachal Pradesh which has made the region relatively inaccessible for developmental planning and infrastructural setup. Educational progress in these states have suffered due to geographic and linguistic barrier, concentration of maximum resources in terms of infrastructure and manpower around major cities, poor economic situation etc. An innovative approach to break these barriers is to take the help of Distance Learning to reach the huge student community. NESAC, established as a unit of Department of Space in Umiam, Meghalaya has a mandate of capacity building in the region. To fulfill the mandate, NESAC, in May 2019, conducted a first-of-its-kind Online Distance Learning Training Program on Remote Sensing \& GIS Applications for students and professionals of the region jointly with IIRS, Dehradun which is having rich experience of conducting Distance Learning Programs in the country. The two week long training program was attended by more than 250 participants in online interactive mode and had an ensemble of lecturers taken from IIRS, Dehradun and NESC both. While faculty of IIRS covered the basics of RS \& GIS, Geo Web Services, GNSS etc; the scientists of NESAC presented on various thematic applications of RS \& GIS conducted by NESAC specific to the region. At the end of theoretical lectures, online exam was also conducted and based on the online evaluation, digital certificates were distributed to the successful candidates. IIRS, Dehradun also extended their help to NESAC in IT infrastructure at all steps of the course. NESAC received large positive feedback of the course, many participants asking for longer duration courses, customized courses and even advanced courses. NESAC has planned to conduct similar course annually.
\end{abstract}

\section{INTRODUCTION}

NESAC conducted a distance learning program jointly with IIRS, Dehradun on "Remote Sensing and GIS- Technological Advances and Applications". This course was designed to provide sufficient knowledge and advanced training in the field of Geospatial domain and Earth Observation applications. One of the objectives of such course isto reach large number of Professionals of user Departments, Students \& Researchers engaged in Urban \& Regional Planning, Geography, Environmental studies, Civil Engineering, Architecture, Agriculture, Horticulture, Hydrology, etc.

This is the first time that NESAC is conducting a joint course in collaboration with IIRS, Dehradun. IIRS, Dehradun has a long experience of conducting such online training programs in various thematic areas of Remote Sensing \& GIS (Gupta, 2011)

\footnotetext{
* Corresponding author
}

The course announcement letters addressed by Director, NESAC were circulated to Line Departments of all the North Eastern State Governments as well as Academic Institutions of the region. The Online mode of the Course allows participants to complete registration process online and they can receive the lecture online through a Virtual Classroom from their own locations without needing to travel to NESAC or IIRS. More than 250 candidates have registered from all over the NE Region as well as from other parts of the Country.

\section{BACKGROUND}

One of the mandates of NESAC has been capacity building in the region. Keeping this in mind, the centre has undertaken ISRO's societal programs like Tele-Education (and TeleMedicine) in the region.

\subsection{Tele-Education}

The difficult geographical terrain of North Eastern Region acts as a geographical divide and it is seen that most of the resources are conglomerated at state headquarters and big cities resulting in remote areas being left out. The same happens with Education Sector as well. Though there is no 
dearth of students, very few schools and teachers are there to teach and the student to teacher ratio becomes poorer in general and fall in the standard of classroom education becomes particularly visible in remote areas in comparison with urban areas. The terrestrial internet connectivity(optical fiber or copper cable based) in these areas have not improved as expected over the years(most areas which are covered by terrestrial internet connection, are served by only one nationalized internet service provider) in comparison to bigger cities.

Though cellular mobile internet is becoming quickly popular with attractive $4 \mathrm{G}$ connectivity options, its penetration is still superficial. Therefore, Satellite based connectivity becomes ideal for these geographic locations. The User Terminals are easy to install, cost effective and provides sufficient bandwidth to cater to educational services. It is a known fact that the broadband satellite links are high latency links due to round trip delay of satellite signals from Earth Stations to Geostationary satellite at $35,768 \mathrm{Km}$ distance in a typical star connected network and the communication protocols are different (DVB-S/T, DVB-S2 or DVB-RCS etc.) than terrestrial internet connection. But the satellite communication fraternity is coming up with innovative techniques for adapting with the high latency(use of techniques like TCP acceleration) and even higher signal power losses with the use of higher frequency bands $(\mathrm{Ku}$ band at $11 / 14 \mathrm{GHz})$ due to the high sensitivity of the frequency band to rain attenuation(techniques like Adaptive Coding \& Modulation in DVB-S2). Using Satellite Communication technology courtesy of satellite bandwidth from ISRO Communication Satellites (GSAT-3 or EDUSAT,INSAT- 4CR, GSAT-18 etc), NESAC has implemented Satellite Communication based Distance Learning via Virtual Classroom mode in all eight states of the region (Gupta, 2016). Currently, there are 350 Satellite Interactive Terminals (SITs) in these eight states with 7 Hubs in a star-connected network. Each state has its own Hub and set of SITs, which are commissioned at Secondary or Senior Secondary level schools or Teacher Training Institutes. Multimedia educational content is generated at the Teaching End(Studio) collocatd at each Hub and is fed to the uplinking chain at Hub with the help of Hub Rack equipments and 3.8 meter Ku-Band VSAT Antenna. The satellite downlinks the same feed in broadcast mode to the SITs. This forms the forward Channel (link). In the return link, the students receiving the program may ask questions to the resource person sitting at the Hub Teaching End which is uplinked as multimedia to the Satellite and received at the Hub using the Return Channel (Link) via Satellite (RCS). The resource person can answer which is similarly broadcast via the satellite as mentioned previously.NESAC has maintained the network, upgraded it with latest peripheral hardware (Computer, UPS, Webcam, TV, Microphone etc) as well as SIT equipments like 1.2 meter VSAT Antenna and its parts etc. In 2017-2018, NESAC spent 10 crores for revival of the whole TeleEducation Network of the region along with setting up 25 new SITs for the state of Manipur. Around 50 programs are being generated every week using these resources and thousands of students are being benefitted from the connectivity which brings to these students of remote location schools quality education breaking the geographic barrier. The student needs not to travel to big cities for education and resource persons also can deliver quality lectures from a single location (Hub) in a state.

\subsection{Capacity Building programs by NESAC}

Over the years, especially from 2015, NESAC has strived to increase its training activity for students and professionals of the region, especially to officials of various State Government Line Departments and students of Remote Sensing, Geographical Information System \& other applications of Space Technology. Being a centre of repute in the region, having valuable experience of handling various projects of State \& Central Governments of the region like Forest Working Plan of various states, North Eastern District Resource Plan(NEDRP), which won the National eGovernance award, Flood Early Warning System(FLEWS) for Assam, Sericulture Information Linkage Knowledge System(SILKS) for the whole country etc and many others, NESAC has the ability to act as a centre of excellence in the region and use space technology inputs for various RS \& GIS applications. But not only using the technology for the sustainable development of the region, NESAC also wishes to put forward a model of inclusive development by sharing the technology through effective capacity building. NESAC has, over the past two years, regularly conducted training programs like Basic Course on RS \& GIS, Advanced course on RS \& GIS etc. With broadening of its spectrum of activities and venturing into new vistas like UAV Remote Sensing (UAVRS) and Global Navigational Satellite System (GNSS), NESAC plans to conduct many more customized courses in the future. It is already conducting training courses tailor-made for State \& Central Government agencies like National Disaster Management Authority (NDMA), Oil \& Natural Gas Commission (ONGC), Agriculture, Water Resource \& Geoscience Departments etc. Recently NESAC has conducted training program for capacity building of professionals from The Bay of Bengal Initiative for Multi-Sectoral Technical and Economic Cooperation (BIMSTEC) countries, namely Bangladesh, Nepal, Bhutan, Sri Lanka, Thailand, Myanmar and India. NESAC has recently set up a capacity building facility, namely NESAC Outreach Facility near NESAC for specifically carrying out trainings and courses and conduction of internship of students. It is having all state- of-the-art facilities.

\subsection{Internet Based Distance Learning}

Though Tele- Education has achieved unthinkable success in the education-hungry region, it has only increased the appetite for better quality educational content. With the improvement of internet connectivity, especially mobile internet services, students at almost any location of the region are now ready to consume quality educational content coming their way. Internet based Distance Learning has revolutionized the world of education (Raju, 2007a) and has played a very significant role in knowledge dissemination and capacity building of the students globally. Understanding the situation and committed to take education to all needy, NESAC planned for capacity building training program using internet connectivity (Raju, 2007b ). IIRS, Dehradun as an academic and training centre of ISRO in India has been at the forefront of adopting the Distance Learning technology and systematically conducting online training programs over the years. As of today, IIRS conducts more than twenty online training programs throughout the country every year and has set up state-of-theart facilities at IIRS, Dehradun including a Studio for digital multimedia content generation and online delivery, IT infrastructure to feed the e-contentinto internet for Live broadcasting. All required modules for conducting online course starting from Course Announcement, Registration of participants, Conduction of Course Lectures, Online Evaluation and Feedback collection for the course\& 
dissemination of Certifcates are developed by IIRS, Dehradun. Hence, it was a natural choice for NESAC to collaborate with IIRS, Dehradun.

\section{METHODOLOGY}

\subsection{Course Announcement}

The course was conceived by Shri PLN Raju, Director, NESAC and accordingly the course schedule was finalized first. Course announcement letters were drafted and finalized with the help of IIRS, Dehradun and sent to all leading Academic Institutions of the region like North Eastern Hill University(NEHU) and other Central and State Government Universities(Tripura University, Mizoram University, Nagaland University etc) and State Government Organizations like State Remote Sensing Agencies(Assam RSAC, Nagaland GISRSC etc.).

\subsection{Online Course Registration}

Interested participants were instructed to register online to the course through IIRS Elearning portal. Course registration portal was open till $26^{\text {th }}$ April 2019 and a total of 256 participants registered in the course. Registered candidates were given login credential to login to IIRS Elearning portal to access the course content. A Screenshot of the IIRS Elearning portal for the specific course showing all registered candidates is shown in Figure 1.

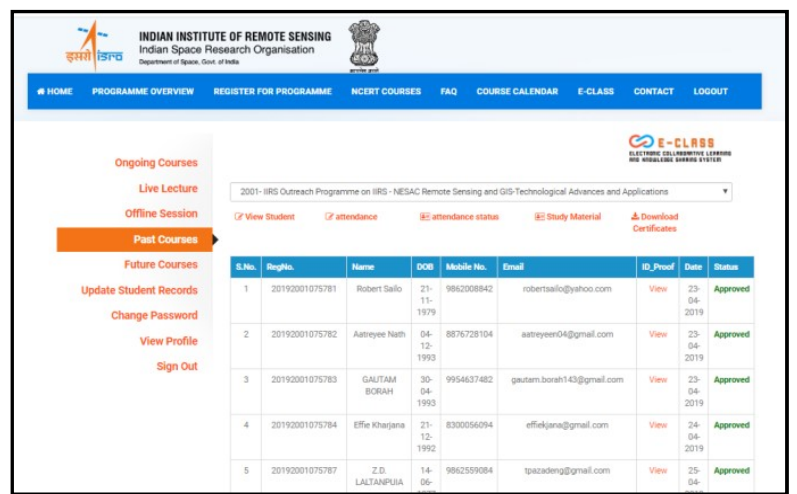

Figure 1. IIRS Elearning portal for the specific course showing details of all online registered candidates.

\subsection{Course Content design and lecture delivery and access scheme}

Each lecture was divided into two sections, first part of 40-50 minutes during which the resource person can deliver the lecture and for the rest 15-20 minutes, participants can interact with the resource person regarding their queries in online mode. For making the queries, the participants could use a microphone or and a webcam as audio and video input devices. Text queries could also be posted to IIRS Elearning portal so that resource person could directly answer seeing the question.

It was decided that for IIRS Lectures, the resource persons will be delivering the lectures from IIRS Studio while NESAC lectures will be delivered from NESAC Outreach Facility Smart Class Room. All lectures were live streamed to IIRS Elearning portal and IIRS Elearning Youtube Channel and archived for seeing later. The course content in the form of live lecture containing lecturer's audio-video, presentation and annotations was captured by IIRS LMS Software and live fed to IIRS Distance Learning Portal, developed by IIRS (https://elearning.iirs.gov.in). The access to IIRS Elearning portal is through online authentication.

For NESAC lectures, it was decided that the lecturer audiovideo-presentation and annotations will be captured through third party software(Go To Meeting) and the composite multimedia content would be sent to IIRS after the completion of the session for editing and uploading to IIRS Elearning Channel for archival purposes. However, for live streaming, the same feed was received by IIRS who would have logged in as a student and upload the whole feed to IIRS Elearning portal for live broadcasting. The interaction session in this case was conducted through logging into IIRS Elearning portal from NESAC end at the end of live lecture.

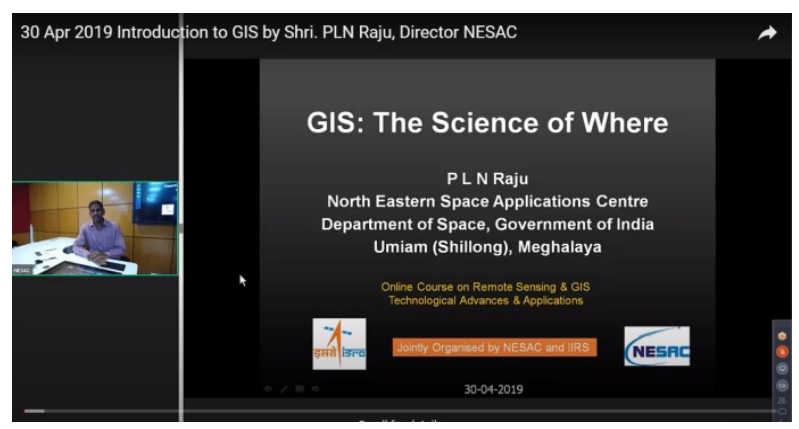

Figure 2. A demonstration of web interface as accessed by participants at IIRS Youtube Channel during a lecture

A participant only required working internet connection (medium bandwidth only) at his/her laptop/desktop system along with peripherals like Microphone/ Webcam which generally come as integrated to most laptops. This meant that the participant could attend the class at a fixed time everyday according to the schedule sitting at his/her convenient location. This was the best part of the online training that regular residential training lacked, especially from the point of view of young professionals and students who could not afford to skip regular work/institutional classes.

\subsection{Course Inauguration}

The course was inaugurated on $29^{\text {th }}$ April, 2019 in a brief program in presence of NESAC staff, student participants as well as the team from IIRS, Dehradun in Online Video Conferencing Mode as shown in Figure 3. The program had inaugural address and a course overview and introduction to the course. This was followed by the inaugural lecture given from IIRS, Dehraddun in Online mode. Participants who logged in with their credentials to IIRS Elearning portal, were able to view the lecture and took part in interaction with the faculty at the end of the lecture. 


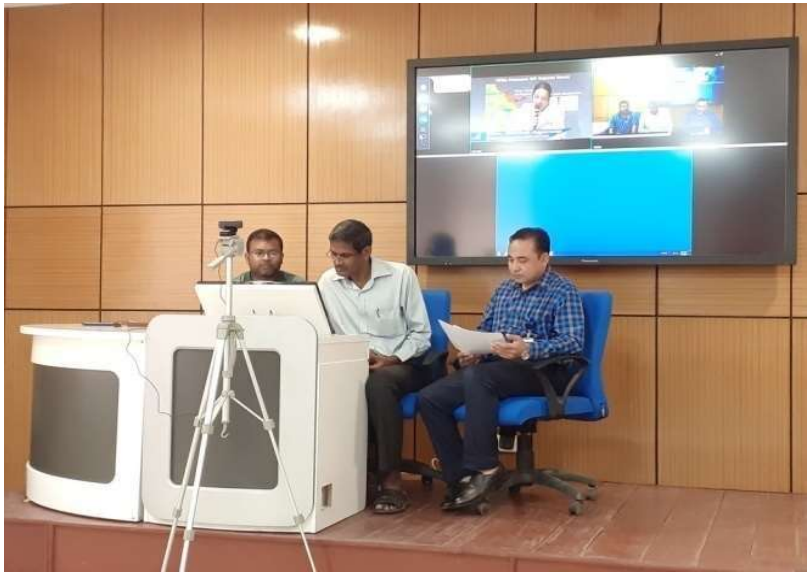

Figure 3. Inauguration of NESAC-IIRS joint course on April 29, 2019 at NESAC with IIRS and participants present via video conferencing

\subsection{Technical Details of the course}

Resource persons were selected from both NESAC and IIRS. The course was scheduled from April 29-May10, 2019. The first week of the course was designed to provide basic knowledge on Remote Sensing, Digital Image Processing, Geographic Information System, Global Navigation Satellite System and Web \& Mobile GIS- Technology \& Applications. The second week of the course has been designed to focus on the various application areas using Space Technology. The application areas that are designed to address during the course are Geo-Web services and Governance Applications, Remote Sensing for Agriculture and Forestry Applications, Remote Sensing Applications in Earth Science and Water Resources, Applications of UAV Remote Sensing and Remote Sensing of Urban and Societal Applications. The resource persons are identified from IIRS and NESAC. The schedules and topics of lectures are given in Figure 4.

\section{IIRS - NESAC Outreach Programm}

on

Remote Sensing and GIS-Technological Advances and Applications

\begin{tabular}{|c|c|c|c|c|}
\hline $\begin{array}{c}\text { Si No. } \\
1\end{array}$ & \multicolumn{2}{|c|}{$\begin{array}{l}\text { Course Name } \\
\begin{array}{l}\text { Remote Sensing and GIS Technotogical } \\
\text { Advances and Applications }\end{array}\end{array}$} & $\begin{array}{c}\text { From } \\
29 \text { April } 2019\end{array}$ & $\begin{array}{c}\text { To } \\
10 \text { May } 2019\end{array}$ \\
\hline Date & Time & \multicolumn{2}{|l|}{ Title } & Faculty \\
\hline $2904 / 2019$ & $1130-1300$ hrs & \multicolumn{2}{|l|}{ Basics of Remote Sensing } & Ms. Manu Mehta \\
\hline $30 / 04 / 2019$ & $1130-1300$ hrs & \multicolumn{2}{|c|}{ Geographic Information System } & Shri PLN Raju, NESAC \\
\hline $01 / 05 / 2019$ & $1130-1300 \mathrm{hrs}$ & \multicolumn{2}{|c|}{ Basics of Digital Image Processing } & Dr. Poonam S Tiwari IIRS \\
\hline $02 / 05 / 2019$ & $1130-1300 \mathrm{hrs}$ & \multicolumn{2}{|c|}{ Global Navigation Satellite System } & Er. Ashutosh Bhardwaj. IIRS \\
\hline $03 / 05 / 2019$ & $1130-1300$ hus & \multicolumn{2}{|c|}{$\begin{array}{l}\text { Web \& Mobile GIS-Technology \& } \\
\text { Applications }\end{array}$} & Shri Kamal Pandey, IRS \\
\hline $06 / 05 / 2019$ & $1130-1300 \mathrm{hrs}$ & \multicolumn{2}{|c|}{ Geoweb services and governance applications } & Dr. Harish Karnatak, IRS \\
\hline
\end{tabular}

Figure 4. A part of NESAC-IIRS Joint course schedule

The classes were held at NESAC Outreach Smart Class Room mostly. Students who registered from NESAC attended the classes and lectures directly there. They attended the classes which were delivered from IIRS as well at the same location. Participants from outside NESAC attended the classes from their own locations. Such a classroom lecture has been shown in Figure 5 and Figure 6.

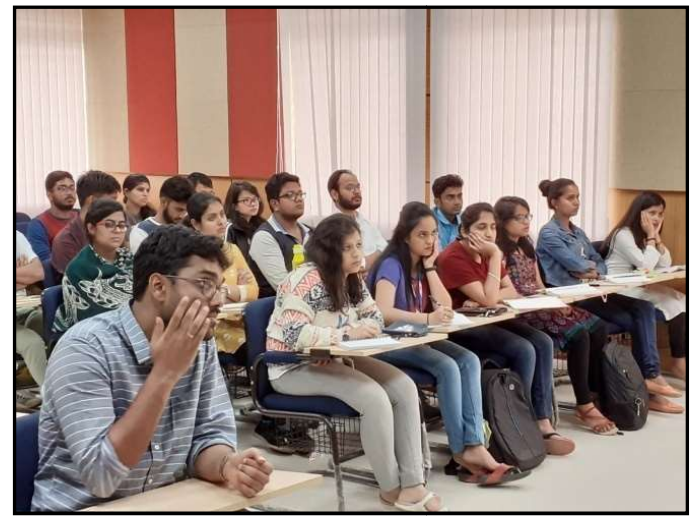

Figure 5. Participants attending live lecture at NESAC Outreach Smart Class Room during the course

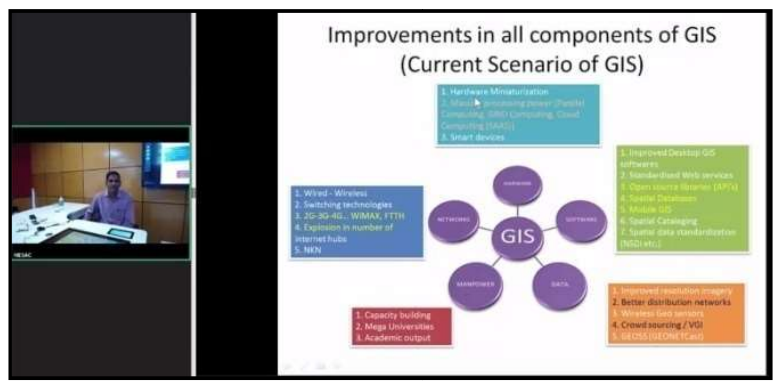

Figure 6. Mr. P. L. N. Raju delivering a lecture during the course on GIS technologies

\subsection{Attendance Management}

Participants' attendances were automatically registered as they logged in during the Live lecture. If someone could not attend the Live lecture, there was a scope for viewing the lecture offline later from IIRS Youtube channel or by logging into IIRS Elearning portal. Thus the attendance of the participants were marked and based on that attendance, participants were allowed/not allowed to sit in the online exams later. A Screenshot of the record for attendance of participants of the course as stored and archived at IIRS Elearning portal is shown in Figure 7. Through Attendance Status option, a participant could see his/her attendance status during the course to improve on the attendance if required. Eligibility for appearing in the course end evaluation was decided based on the attendance. Once attendance was marked automatically by Elearning portal for a candidate, it had to be validated by Course Coordinator to finally reflect in the portal.

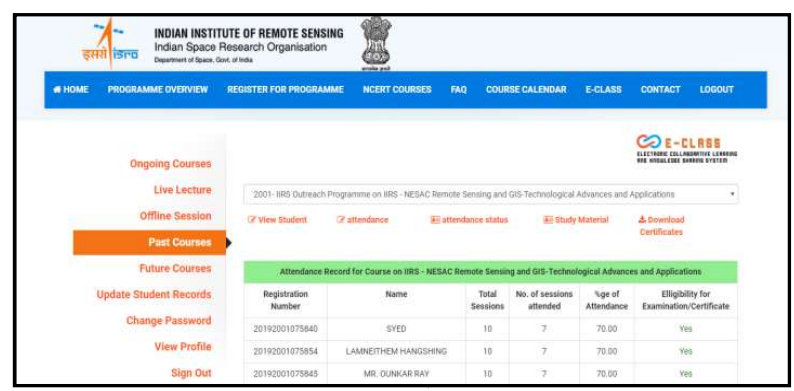

Figure 7. Attendance Marked for all participants of the course as displayed in IIRS Elearning portal 


\subsection{Online Examination\& Evaluation}

The examination of the course was scheduled on $05^{\text {th }}$ July 2019 in online mode through computer based test. Participants, whose attendance during the course were over eighty percent, were allowed to sit for the online exam. For the examination, regional academic institutions which were conducting IIRS Courses regularly, were contacted for their consent to conduct tests of candidates at their premises and the participants were intimated the list of such institutes for choosing their centre of choice to appear for the test.

Total 53 institutions from the eight states of NER were selected for the examinations. These were situated in 50 major cities of the NER. Each centre coordinator was responsible for conducting the online examination at his/her institution premise on the selected day of examination. The coordinator would check the registration number of all appearing students, matching them with the list of assigned candidates to that institution. This list was forwarded to each coordinator by Course Coordinator. Then, the coordinator would make seating arrangement for the students so that each student gets a computer system with working internet connection for giving the exam. The coordinator was also responsible for invigilating the candidates throughout the exam duration.

A Screenshot of the list of institutions which was disseminated to the students containing full details of the institutions and the centre coordinators is shown in Figure 8.

\begin{tabular}{|l|l|l|l|}
\hline Name of University/ College / Instituion & tate & ity & lame \\
\hline Nagaland University, Kohima, Nagaland & Nagaland & Lumami & Wangshimenla Jami \\
\hline Manipur Science and Technology Council, Imphal, Mä Manipur & Imphal & R K Pritamjit Singh \\
\hline Manipur University, Imphal, Manipur & Manipur & Imphal & Arun Kumar \\
\hline Mizoram University, Aizawl, Mizoram & Mizoram & Aizawl & C Lalnuntlunga \\
\hline KAzIRANGA UNIVERSITY & Assam & JORHAT & Sajal Saha \\
\hline University Of Science And Technology, Meghalaya & Meghalaya & Ri-Bhoi & Shamikhu Changmai \\
\hline Tripura University, Agartala, Tripura & Tripura & Suryamani N & Nibedita Das (Pan) \\
\hline Tezpur University, Sonitpur, Assam & Assam & Napaam & Anjan Kumar Bhatta \\
\hline Tata Institute Of Social Sciences, Guwahati, Assam & Assam & Guwahati & Pijush Kumar Dutta \\
\hline Royal Global University & Assam & Guwahati & Ghanshyam Kumar \\
\hline Kabi Nazrul Mahavidyalaya, Sonamura, Tripura & Tripura & Sonamura & Kuldip Gosai \\
\hline Sikkim University, Gangtok, Sikkim & Sikkim & Gangtok & Elangbam Ishwarjit \\
\hline
\end{tabular}

Figure 8. A Screenshot of the List of Academic Institutions and Centre Coordinators for the online examination

After all the centers and coordinators for those centers were decided, a question bank was made by compiling objective type questions taken from the resource persons. Though software available at IIRS, randomized online question papers were made and students received the questions on the day of examination after logging in with exam specific login and password. The questions were objective type, the paper comprised of a total of 60 questions and the duration of the test was one hour. At the end of the test, marks were computed instantly and intimated to the examinee on his/her computer screen. A Screenshot of such marks obtained by a candidate at the end of her examination is given in Figure 9.

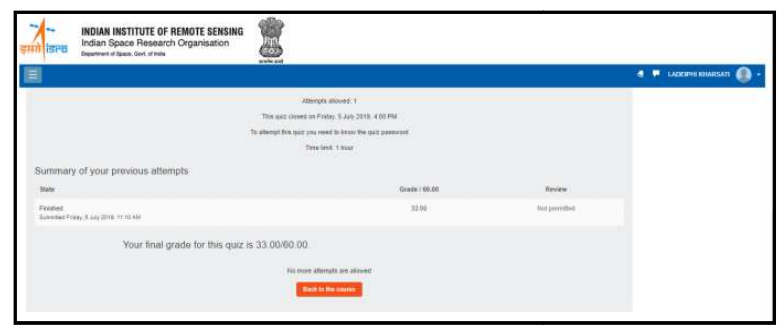

Figure 9. Screenshot of marks obtained by a candidate intimated right after completion of examination

Thus the examination procedure was completely online and maintained by IIRS, Dehradun.

\subsection{Dissemination of certificates and conclusion of course}

At the end of examination, the digital certificates were generated by IIRS Learning Management System (LMS) Software (Raju, 2008) and uploaded into the course specific portal for successful participants to download. A Screenshot of the certificates download section at the portal is shown in Figure 10. As these certificates are digitally generated and archived at IIRS Elearning portal, it can be downloaded again by requesting the course coordinator through proper channel for later requirement.

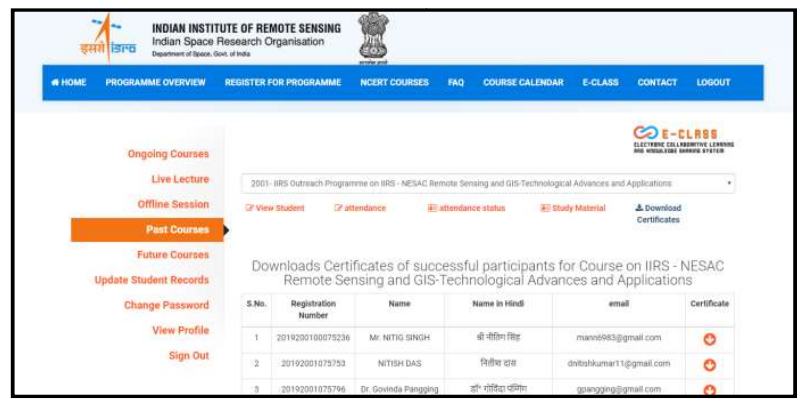

Figure 10. Course specific certificate download section at the IIRS E-learning portal

A demo certificate is shown in Figure 11. It is digitally signed by Director, IIRS, Director, NESAC, Head, Geo-Web Services, IT \& Distance Learning Department, IIRS and Course Coordinator at NESAC. Every certificate was Bilingual, mentioning the name of the candidate and the name of the course.

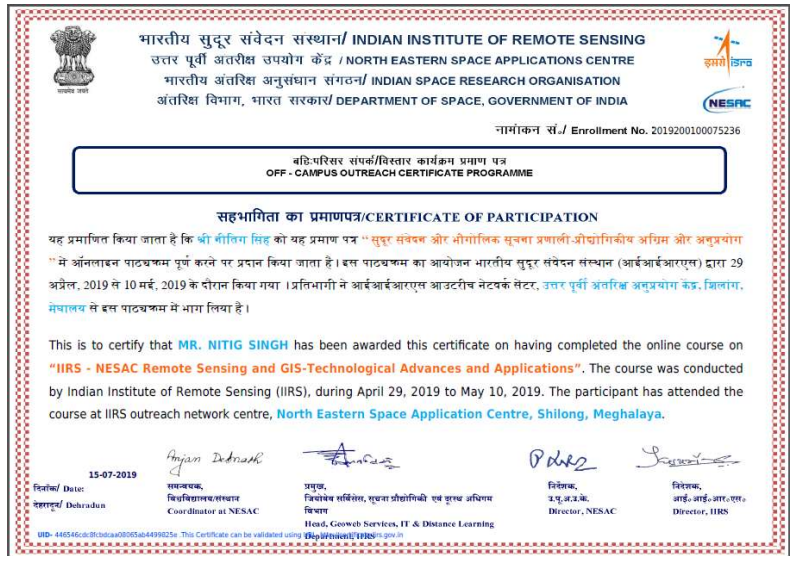

Figure 11. A Certificate of the IIRS-NESAC joint course

Finally the course conclusion was arranged in a panel discussion through video conference with all the participants and NESAC,IIRS faculties.

\section{DISCUSSION}


Online Distance Learning is an effective, affordable and timesaving technology with a potential to reach unlimited number of students (Raju 2010) which alleviates geographic, demographic and economic barriers and unifies all searching quality education. NESAC has started its journey in this path of future and wishes to continue the journey for years to come. The feedbacks of the course, received online from the participants, were encouraging and NESAC wishes to incorporate the suggestions in its next course. NESAC also intends to achieve self-reliance in conducting such courses as soon as possible so that customized courses can be prepared and targeted for specific groups (Raju, 2011; Raju, 2012)

\section{CONCLUSION}

Technical detail of a first of its kind online training program on the theme of RS \& GIS conducted in NER of India has been given. Background and requirement for such online course for NER has been established. Detailed methodology for conduction of the course has been presented. The course has proved to be very successful as young professionals from all eight NER states enrolled for the course in large numbers. Though all of them could not attend the live classes due to various technical and other problems, features such as offline attending, offline submission of questions and interaction with resource persons stood apart and were extremely popular. Systematic management of course material access through $\mathrm{ftp}$, youtube and IIRS Elearning portal, arrangement of examination centres in all major cities of NER, objective based online examination and online dissemination of certificates made attending the course really easy for the participants. Hence, it can be concluded that the online mode of conduction of such short term course is extremely successful and should be adopted even more in future by other leading academic institutions of the region. NESAC and IIRS can help such institutes in whichever way required.

\section{ACKNOWLEDGEMENTS}

Authors acknowledge the support of Director, IIRS for agreeing to support NESAC in conduction of the course. Authors also acknowledge the support of Geo Web Services Division of IIRS and the studio technicians especially for all the required technical support in conduction of the course. Finally we acknowledge the support of all resource persons from IIRS as well as NESAC who agreed to give lectures for the course, prepared lecture contents, delivered the lectures, answered the questions and prepared questions for the examination.

\section{REFERENCES}

Gupta, P.K., Raju, P.L.N., and Roy, P.S., 2011. "User Response Analysis of IIRS Geomatics EDUSAT Distance Learning Program and Future Challenges." ISPRS VI/4 International Workshop on Multinational Geomatics Capacity Building - Achievements and Challenges", IIRS, Dehradun, India, April 7-8, 2011.

Gupta, S., Karnatak, H., and Raju, P. L. N.: Geo-Informatics in India: Major Milestones and Present Scenario, Int. Arch. Photogramm. Remote Sens. Spatial Inf. Sci., XLI-B6,111121,https://doi.org/10.5194/isprs-archives-XLI-B6-111-2016, 2016.
Raju, P.L.N., Dadhwal, V.K., and Jeganathan, C., 2007, "GIS Education and Training at Indian Institute of Remote Sensing", GIS Development Asia Pacific, , Vol 11, Issue 3, Mach 2007.

Raju, P.L.N., and Dadhwal, V.K., 2007. Four decades of capacity building in applications of space-based earth observation and Geoinformatics at Indian Institute of Remote Sensing, Proceedings of 58th International Astronautical Congress, organized at NRSA, Hyderabad during Sept. 24-28, 2007. IAC-07-E1.I.08

Raju, P.L.N., Dadhwal, V.K., Verma, Mamta., Jeganathan, C., Kumar, Minakshi., and Kumar, Anil., 2008, "Indian Experiences for University Level Capacity Building in Geomatics using EDUSAT Satellite", The International Archives of the Photogrammetry, Remote Sensing and Spatial Information Sciences. Vol. XXXVII. Part B6a. Beijing 2008, pp 229-234

Raju, P.L.N., Dadhwal, V.K., 2010, "IIRS Perspective on Lessons from Implementation of a Cross Border Joint Education Program", ISPRS Archives - Volume XXXVIII Part 6, 2011, ISPRS Mid-Term Symposium Commission VI CrossBorder Education for Global Geo-information June 2-4, 2010, Enschede, The Netherlands, Editor(s): Martien Molenaar, TsehaieWoldai, SaskiaTempelman

Raju, P.L.N., Gupta, P.K., and Roy, P.S., 2011. "Satellite Based Live and Interactive Distance Learning Program in the field of Geoinformatics - A Perspective of Indian Institute of Remote Sensing, India." ISPRS WG VI/1,2 Workshop ELearning 2011 within ACRS. 4-6 October 2011, Taipei, Taiwan.

Raju, P.L.N., and Gupta, P.K., 2012, "Satellite based Education and Training in Remote Sensing and Geo- Information: an ELearning Approach to Meet the Growing Demands in India." International Archives of Photogrammetry, Remote Sensing and Spatial InformationScience, XXXIX-B6(Vol), 25-29, 2012 doi:10.5194/isprsarchives-XXXIX-B6-25-2012. 